\title{
LAS CAMPAÑAS DE VACUNACIÓN CONTRA LA POLIOMIELITIS EN ESPAÑA EN 1963*
}

\author{
Juan Antonio Rodríguez Sánchez
}

Universidad de Salamanca

\author{
Jesús Seco Calvo
}

Universidad de León

\section{RESUMEN}

En 1963 coexistieron en el tiempo dos campañas de vacunación antipoliomielítica: la llevada a cabo con vacuna Salk por el Seguro Obligatorio de Enfermedad y la experiencia piloto con vacuna oral Sabin que promovió la Dirección General de Sanidad. La simultaneidad obedecía a la pugna entre ambos organismos por controlar la Medicina Preventiva en España. El Seguro Obligatorio de Enfermedad utilizó la vacunación antipolio para promocionarse socialmente en unos momentos de gestación de la Ley de Bases de la Seguridad Social. En estas circunstancias, la Dirección General de Sanidad debió anticipar su campaña de vacunación mediante un ensayo de una novedosa vacuna trivalente oral en la provincia de León, aspectos que fueron ocultados a la población. La reivindicación de su competencia en la prevención y la necesidad de una respuesta masiva ante una vacunación voluntaria originaron una singular campaña publicitaria de añejos mensajes pero en novedosos medios de comunicación.

PALABRAS CLAVE: Poliomielitis. Medicina preventiva. Vacunación. Divulgación. Política sanitaria.

\section{VACCINATION CAMPAIGNS AGAINST POLIOMYELITIS IN SPAIN IN 1963}

\section{ABSTRACT}

Two anti-poliomyelitic vaccination campaigns coexisted in 1963: the Salk vaccine used by the Compulsory Health Insurance and the pilot experience with the oral Sabin vaccine promoted by the Health General Office. This simultaneity of campaigns was due to the interest that both bodies had to control the Preventive Medicine in Spain. The Compulsory Sickness Insurance used the antipolio vaccine to promote itself socially in a time when the Basic Law on Social Security was being developed. Under these circumstances, the Health General Office allegedly brought forward its

* Trabajo realizado en el marco del proyecto HUM2005-07378-C03-03 financiado por el Ministerio de Educación y Ciencia. 
vaccine campaign by using a test of an innovative oral trivalent vaccine in the province of León, something which was hidden to the public. The Health General Office's claim of competence in prevention and the need of a massive response to a voluntary vaccine led to a singular advertising campaign with old messages in innovative means of communication.

KEY WORDS: Poliomyelitis. Preventive medicine. Vaccination. Dissemination. Health policy.

\section{INTRODUCCIÓN}

El 26 de enero de 1963 el Ministerio de Gobernación español dictaba las pautas para proceder a la vacunación antipoliomielítica a través de una Orden enmascarada bajo el título: «normas en cuanto a las obligaciones y facultades de la Dirección General de Sanidad en materia de Medicina Preventiva (vacunación antipoliomielítica)». El contenido de la Orden se deslizaba por el difícil equilibrio de las ambigüedades y los posicionamientos velados: un pronunciamiento en defensa de la vacunación oral con «virus vivo tipo Sabin» pero una constatación de su inviabilidad en esos momentos, una voluntad de erradicación de la polio pero un mantenimiento de la vacuna Salk (aunque se introdujese su gratuidad), una reivindicación de sus funciones de control sanitario pero una obligada asunción de la creciente autonomía del Seguro Obligatorio de Enfermedad (SOE) $)^{1}$. Se sentaban así, aunque de manera un tanto esquiva, las bases para el inicio de la campaña de vacunación más ambiciosa acometida hasta entonces en España, tanto por tratarse del preámbulo para la instauración de las vacunaciones sistemáticas y los calendarios vacunales, como por las estrategias diseñadas para la difusión de la misma entre la población.

La expansión de la poliomielitis a nivel mundial también incidió en España y las décadas de los cincuenta y sesenta del siglo XX supusieron un aumento de su morbilidad y mortalidad, dudosamente cuantificadas y nunca reconocidas públicamente en sus auténticas dimensiones. Si en otros países occidentales estas fechas coincidían con el resurgir tras guerra y posguerra, esta circunstancia era más determinante en España al encontrarse bajo una dictadura fascista, pues las políticas desarrolladas para la «protección de la infancia» —interpretada por el franquismo como bien social antes que como sujetos- habían derivado más hacia la enseñanza y adoctrinamiento de las madres desde la coartada científica de la puericultura, que hacia una mejora de la sanidad pública² ${ }^{2}$ En este con-

1 Orden de 26 de enero de 1963 de Ministerio de la Gobernación (B.O.E., 30-1-1963, n 26, pp. 1649-50).

2 AMICH ElíAs, C. (2005), El poder y los derechos del niño en el franquismo, Salamanca, Ediciones Universidad de Salamanca (pass., pero especialmente pp. 430-440); BERNABEU 
texto, la enfermedad y sus secuelas eran un desafío al propio discurso del Régimen, pronatalista y regeneracionista; el niño con secuelas poliomielíticas suponía la exhibición paradójica del pueblo numeroso, sano y fuerte concebido para forjar una España Imperial Grande y Libre ${ }^{3}$.

Las campañas de vacunación contra la poliomielitis fueron acogidas mundialmente, pese a las controversias sobre tipos de vacunas y efectos indeseables, como la única forma de combatir la enfermedad ${ }^{4}$. En España, la introducción e implantación de las vacunas se iban a desarrollar en un marco bastante diferente al de los vecinos del norte y centro de Europa. Las frías ponderaciones sobre número de afectados y cuantía económica de una vacuna importada, constituyeron sólo un prólogo de una batalla que no se libraba exclusivamente contra la polio, sino entre los dos núcleos más significativos del poder sanitario de la época: la Dirección General de Sanidad (DGS) y el Seguro Obligatorio de Enfermedad (del Instituto Nacional de Previsión) ${ }^{5}$. El

Mestre, J. (2002), Madres y enfermeras. Demografía y salud en la política poblacionista del primer franquismo, 1939-1950, Revista de Demografia Histórica, 20(1), pp. 123-143; RoDRÍGUEZ OCAÑA, E. (1998), La construcción de la salud infantil. Ciencia, medicina y educación en la Transición Sanitaria en España, Historia Contemporánea, 18, pp. 19-52.

3 Cenarro, A. (2006), La sonrisa de Falange. Auxilio Social en la guerra civil y en la posguerra, Barcelona, Crítica, p. 114.

4 Omitimos las obras sobre historia de la poliomielitis (reseñadas en otros artículos de este volumen) para dar cuenta de las aportaciones de mayor interés sobre la vacunación, sus polémicas y sus implicaciones científicas y económicas: AITKEN, S. (2004), The Beginning of the End: The Vaccine Story. En Aitken, S., D’Orazio, H., Valin, S., Walking Fingers. The Story of Polio and Those Who Lived With It, Georgetown-Ontario, Véhicule Press, pp. 195207; BArreto, L., VAN EXAN, R., RutTy, C.J. (2006), Polio vaccine development in Canada: Contributions to global polio eradication, Biologicals, 34, pp. 91-101; GoULD, T. (1995), A Summer Plague. Polio and its Survivors, New Haven, Yale University Press, pp. 159-187; LINDNER, U., BLUME, S. (2006), Vaccine Innovation and Adoption: Polio Vaccines in the UK, the Netherlands and West Germany, 1955-1965, Medical History, 50, pp. 425-446; Moulin, A.M. (dir.) (1996), L'aventure de la vaccination, Lyon, Fayard, pp. 297-340. Para España contamos con el análisis de los usos de las campañas por BALLESTER, R. (2008), La presentación internacional de las campañas de vacunación contra la poliomielitis en España. En PERDiguero GIL, E. (coord.), Las vacunas. Historia y actualidad, Menorca, Institut Menorquí d'Estudis, pp. 123-138.

5 La transformación de competencias sanitarias en médicas, la absorción del SOE de funciones clásicas de la Salud Pública y diferentes tensiones entre estos organismos son estudiadas por: De Miguel, J.M. (1979), La sociedad enferma: Las bases sociales de la política sanitaria española, Madrid, Akal Editor, pp. 25-54; MARSET CAMPOS, P., SÁEZ GóMEZ, J.M., Martínez Navarro, F. (1995), La Salud Pública durante el franquismo, Dynamis, 15, pp. 211-250, pp. 236-240; MUÑOZ MACHADO, S. (1995), La formación y la crisis de los servicios 
desarrollo mediático de las campañas obedeció previsiblemente a criterios de propaganda política mediante la imagen de logros del Régimen ${ }^{6}$, pero exhibiendo en esta ocasión una novedosa dualidad al tratarse de un público tanteo de fuerzas de cada sector sanitario en la lucha por la Medicina Preventiva ${ }^{7}$.

La Orden citada al comienzo de este artículo suponía una declaración de intenciones en la campaña para la erradicación de la polio. Sin embargo, lo que en ningún momento aparecía explícito era que el Seguro Obligatorio de Enfermedad (SOE) había iniciado ya su campaña - pero con vacuna Salk- y que la implantación de la vacunación Sabin de la DGS iba a pasar previamente por un macroensayo en dos provincias españolas. Esa campaña piloto (llamada así entre los círculos de la sanidad médica y «campaña nacional» para el resto de los médicos y de la población a quienes se les ocultó el carácter de ensayo) se llevó a cabo en las provincias de Lugo y León en un clima de enfrentamiento entre los responsables nacionales y locales de la Dirección General de Sanidad y del Seguro Obligatorio de Enfermedad que saturaron la

sanitarios públicos, Madrid, Alianza Editorial, pp. 72-83; RodríGUEZ OCAÑA, E. (2001), The Politics of Public Health in the State-Managed Scheme of Healthcare in Spain (1940-1990). En Löwy, I., Krige, J. (eds.), Images of Disease: Science, Public Policy and Health in Postwar Europe, Luxembourg, Office for Official Publications of the European Communities, pp. 187-210; RodríGuez OcAÑA, E. (2002), Los servicios de Salud Pública en la España contemporánea, Revista de Trabajo Social y Salud, 43, pp. 91-116, pp. 104-106; TUELLS HerNÁNDEZ, J. (2008), Los testimonios de los expertos y su participación en las primeras campañas de vacunación antipoliomielítica en España. En ORTIZ GÓMEZ, T. et al. (coord.), La experiencia de enfermar en perspectiva histórica, Granada, Universidad de Granada, pp. 321-324.

6 Para la utilización de las epidemias como oportunidad de legitimación del Régimen véase JiMÉNEZ LuCENA, I. (1994), El tifus exantemático de la posguerra española (19391943). El uso de una enfermedad colectiva en la legitimación del Nuevo Estado, Dynamis, 14, pp. 185-198. Sobre el uso de los medios de comunicación para la propaganda política ligada a temas sanitarios véase, aunque para períodos anteriores, el uso de la radio en JIMÉNEZ LUCENA, I., Ruiz SOMAVIlla, M.J., CASTEllanos GuerRero, J. (2002), Un discurso sanitario para un proyecto político. La educación sanitaria en los medios de comunicación de masas durante el primer franquismo, Asclepio, 54(1), pp. 201-218; el cartelismo, CASTEjón, R., PerdigueRO, E., BALlESTER, R. (2006), Los medios de comunicación al servicio de la lucha antivenérea y la protección de la salud materno-infantil (1900-50), História, Ciencias, Saúde - Manguinhos, 13(2), pp. 411-437; o el cine, MEdinA DomÉnECH, R., MEnÉNDEZ, A. (2005), Cinematic representations of medical technologies in the Spanish oficial newsreel, 1943-1970, Public Understanding of Science, 14, pp. 393-408.

7 Enfrentamientos anteriores de sectores próximos a la sanidad y la infancia, como los habidos entre Sección Femenina y Auxilio Social, no se libraron en los medios de comunicación de esta forma manifiesta, CENARRO (2006). 
prensa de réplicas y contrarréplicas, convertidas en confuso mensaje para una población ajena al auténtico tema del debate.

El mensaje como propaganda, su difusión, recepción ${ }^{8}$ y, especialmente, la ausencia de la misma son estudiados en este trabajo a partir de fuentes orales, archivísticas e impresas. La hemerografía fundamental ha sido la de las referidas provincias «piloto» ${ }^{9}$ : Lugo (El Progreso y Hoja del Lunes) ${ }^{10}$ y, para León, prensa del Movimiento (PROA) y prensa católica (Diario de León) ${ }^{11}$. La importancia de las fuentes orales ha sido capital para esta última provincia debido a la ausencia de fuentes archivísticas. Gracias a la labor de José Fernández Arienza, hemos contactado con cinco médicos de Asistencia Pública Domiciliaria (APD) que ejercieron en diversas zonas de la provincia de León, de los cuales hemos recuperado dos relatos a partir de entrevistas semiguiadas: las de Antonio Mallo González, médico en San Emiliano, y Antonio Silván Garrachón, que ejercía en Chozas de Abajo ${ }^{12}$.

8 Igartua, J.J., Humanes, M.L. (2004), Teoría e investigación en comunicación social, Madrid, Síntesis, pp. 25-34.

9 Rodríguez Sánchez, J.A. y Seco Calvo, J. (2008), Publicaciones periódicas: de la prensa general a las revistas científicas. En PitA, J.R., Rodríguez SÁnchez, J.A., PereirA, A.L., Seco CAlvo, J. (coords.), A poliomielite na Peninsula Ibérica. Reflexoes para a sua compreensao histórica ( $7^{\circ}$ Coloquio Internacional Temas de Cultura Científica), Coimbra, Imprensa da Universidade de Coimbra [Colecçao Ciencias e Culturas] (en prensa).

10 Este último sólo ha ofrecido tres noticias 27-5, 4-11 y 11-11.

11 Para el conocimiento de la prensa regional hemos partido de la consulta de los Anuarios de la Prensa Española. Sobre la prensa castellano-leonesa y, en particular, la de León, véase AlmuiñA, C. (2006), Radiografía de la prensa de Castilla y León. En La prensa diaria en Castilla y León (1856-2006), Salamanca, Junta de Castilla y León - Fundación Siglo para las Artes de Castilla y León, pp. 131-137; LUCAS DEL SER, C. de (2006), Ibid, pp. 179-191 y Carro Celada, J.A. (1984), Historia de la prensa leonesa, León, Diputación Provincial de León. Para Lugo, hemos usado como obra de referencia SAnTOS GAYOSO, E. (1990), Historia de la prensa gallega 1800-1986, Sada - A Coruña, Ediciós do Castro. Sobre las características de la prensa en el franquismo: VÁzQuez VÁzQuEZ, M.R. (2005), La prensa del Movimiento en los fondos de la Hemeroteca Nacional. De la prensa de Falange a los Medios de Comunicación Social del Estado (1936-1982), Madrid, s.n.; SÁnchez ARANDA, J.J., BARRERA, C. (1992), Historia del periodismo español. Desde sus orígenes hasta 1975, Pamplona, EUNSA; TERrón MONTERo, J. (1981), La prensa en España durante el régimen de Franco: un intento de análisis político, Madrid, Centro de Investigaciones Sociológicas.

12 El principal obstáculo ha sido el fallecimiento de la mayor parte de los médicos que se encontraban en ejercicio en ese momento. En segundo lugar, los médicos identificados y contactados, reiteraron que no recordaban ninguna campaña de vacunación en especial, ni casos de polio o sus secuelas. Como se verá en el texto, esta ausencia de recuerdos ratifica algunas de las hipótesis expuestas. 
«NUEVE VECES MÁS BARATA DE LO QUE PARECE»: LA VACUNA SALK EN ESPAÑA (1958-1963)

El texto de la Orden de 26 de enero de 1963 comenzaba por glosar la labor llevada hasta ese momento en la prevención de la poliomielitis:

«[...] desde el año 1958 los Servicios competentes de aquel Centro directivo [la Dirección General de Sanidad] desarrollaran una campaña sistemática de vacunación entre los distintos sectores de la población, habiéndose ya aplicado la vacuna tipo Salk a más de un millón de niños españoles, obteniéndose de tal campaña y de los estudios antes referidos, importantes experiencias que han sido debidamente recogidas en revistas y publicaciones profesionales» ${ }^{13}$.

Palabras que correspondían, como veremos, más a una estrategia que a una realidad, pues ni la campaña pudo ser sistemática, ni llegó a todos los sectores de la población.

Efectivamente, en 1958 la DGS dio comienzo a la vacunación antipoliomielítica con virus muertos tipo Salk. Los dirigentes habían considerado que las características de la vacuna dotaban de complejidad a la labor, tanto por administrarse en tres dosis inyectables - lo que implicaba tiempo y personal- como por la necesidad de conservación, lo que se traducía en un encarecimiento para su traslado y aplicación. Este fue el principal motivo esgrimido por el Gobierno para que la vacunación no fuese gratuita para todos $\mathrm{y}$, consecuentemente, impedía darle carácter obligatorio e incluso hacía desaconsejable insistir demasiado en su publicidad, pese a lo cual algunas declaraciones de Juan Bosch Marín (Jefe de Puericultura de Sanidad Nacional, académico y presentado en los medios de comunicación como el gran experto nacional en poliomielitis, dados sus cargos de Vicepresidente de la Asociación Europea Contra la Poliomielitis y Presidente de la Comisión Española en el V Symposium celebrado ese año en Madrid) ${ }^{14}$, fueron reflejadas en prensa con un retorcido titular: «La vacuna es cara, pero es nueve veces más barata

13 Orden de 26 de enero de 1963 de Ministerio de la Gobernación (B.O.E., 30-1-1963, nº 26, pp. 1649-50, p. 1649)

14 En el análisis de la prensa diaria, para el período 1954-1967, Bosch Marín es el personaje más citado (sólo superado por Salk), más que García Orcoyen (MuÑOZ SiNGI, G. (2007), La poliomielitis en la prensa salmantina (1954-1967), Salamanca, Universidad de Salamanca [Tesis]). El papel de Bosch Marín en la vacunación contra la polio es analizado con detalle por BALLESTER (2008). 
de lo que parece» ${ }^{15}$, basándose en el peregrino razonamiento de que los viales contenían $9 \mathrm{cc}$, es decir, nueve dosis.

Esos «distintos sectores de la población», aludidos en la ley, basaban su distinción en su nivel económico. La DGS había establecido tres grupos (beneficencia, débiles económicos y pudientes) para aplicar diferentes tasas a la vacuna. Si los acogidos a alguna institución benéfica o incluidos en los padrones de beneficencia municipales pudieron acceder a la vacunación gratuita, ese poco definido grupo de «débiles económicos» tuvo que abonar tres pesetas por dosis, es decir, un total de nueve pesetas para completar la vacunación. Para quienes no entraban en esta categoría vacunar a un hijo contra la poliomielitis con vacuna Salk les costaba 27 pesetas (nueve pesetas por dosis) ${ }^{16}$.

La vacunación a los niños encuadrados como de beneficencia fue llevada a cabo directamente por la DGS a través de sus Jefaturas Provinciales y, si en éstas se consideraba oportuno, de los Médicos Titulares municipales. Era la DGS la que proveía de vacuna, previa petición, no sólo a las Jefaturas Provinciales, sino también a otros organismos de la beneficencia como la Delegación Nacional de Auxilio Social que se encargaba de distribuir la vacuna entre sus diferentes instituciones, dando prioridad a las de internamiento. Justino Rodríguez de Alarcón (Jefe del Servicio Médico Central de la Delegación Nacional de Auxilio Social desde 1958), informó en 1963 de su importante papel, con 60.622 niños vacunados, pese a las dificultades ocasionales para obtener una vacuna escasa y cara ${ }^{17}$.

Las Jefaturas Provinciales de Sanidad actuaban de intermediarias con la DGS. A través de los planes municipales de vacunación (que habían solicitado a las Alcaldías) y la información recabada por los médicos de APD a través de los padrones y el propio conocimiento del vecindario, se estimaba el número de niños a vacunar, el nivel económico familiar y las dosis precisas, que las Jefaturas Provinciales pedían a la DGS. Habitualmente, las dosis enviadas eran inferiores a las solicitadas y eran frecuentes los escritos de los Jefes Locales de Sanidad reclamando un envío mayor. Claro está que la de-

15 La Gaceta Regional (Salamanca), 17-4-1958, p. 7.

16 «Circular del Inspector General de Sanidad, 10-4-1961», A.H.P. Lugo, Fondos de Sanidad, Caja 27039. Esta actividad de Auxilio Social se produce en una fase tardía en la que han quedado restringidas sus ambiciones de unificación y control de las actividades benéfico sanitarias, dando un giro hacia planteamientos caritativos más tradicionales. En 1962 pasó a ser organismo autónomo de la Administración del Estado (CENARRo (2006), pp. 175-178).

17 AGA, Grupo de Fondos: Cultura, Fondo: 122; Caja 571 (Sig. Top. 16/6164) 
manda se producía en caso de gratuidad, pues como comunicaban los Jefes Locales de Sanidad, en caso contrario no había vacunación ${ }^{18}$.

No obstante, es necesario precisar que este sistema organizativo que observamos en Lugo no puede ser extrapolable a las restantes provincias: en el caso de León, ninguno de los médicos titulares recuerda haber practicado una vacunación contra la polio de tipo inyectable o que fuese de pago:

«No, no la conocí [la vacuna Salk] Yo, cuando empezó allí la campaña esa, que ya le digo que fue..., se desplazó allí el Jefe Provincial de Sanidad con algunas enfermeras era ya el líquido, las gotas... [...] Yo anteriormente no, no conocí. Lo único que se vacunó, que yo vacunaba anteriormente, era la antivariólica [...] Pero de otras vacunas entonces no se hacía» ${ }^{19}$.

Cabría, por tanto, cuestionar también en este aspecto la auténtica extensión de las campañas con Salk de la Dirección General de Sanidad.

La ineficacia de estos tímidos intentos de campañas que no cubrían a toda la población se pusieron de manifiesto, año tras año, en número de afectados: las tasas de morbilidad y mortalidad conocieron un enorme ascenso desde 1958, superando las tasas de los brotes de 1950 y 1952. Si en 1957 la tasa de morbilidad era de un 3,12 (por cien mil), en 1958 pasó a ser de 7,00 y en 1959 alcanzaba una cota máxima de $7,12^{20}$. Pero eran datos aproximativos, pues Sánchez Villares y Álvarez Suárez, mediante un cuestionario sobre aspectos epidemiológicos y clínicos de la poliomielitis paralítica (la más evidenciable), hacían patente la disparidad entre los datos estadísticos oficiales y la realidad, calculando «que un 50\% de casos no figuran incluidos en las Jefaturas Provinciales de Sanidad» ${ }^{21}$. A ello habría que añadir dos problemas habitualmente silenciados: los casos de polio posvacunal y las vacunaciones incompletas ${ }^{22}$. Respecto a las limitaciones (o consecuencias) de la vacuna, en

18 «Respuesta del Jefe Local de Sanidad de Friol, 5-2-1962», A.H.P. Lugo, Fondos de Sanidad, Caja 27038.

19 Antonio Mallo, entrevista realizada el 15-8-2008. Antonio Silván, entrevista realizada el 13-9-2008, coincide en lo mismo.

20 Pérez Gallardo, F., NÁjera Morrondo, E., Ruiz Falcó, F. (1963), Epidemiología de la poliomielitis en España (Estudio de la morbilidad y mortalidad durante los años 19311935 y 1940-1962), Revista de Sanidad e Higiene Pública, 37(11-12), pp. 454-470, p. 456.

21 Sánchez Villares, E., Álvarez SuÁrez, P.V. (1962), La Poliomielitis en la Región Castellano-Astur-Leonesa de Pediatría (1950-1961). Resultados de una encuesta, Boletín de la Sociedad Castellano-Astur-Leonesa de Pediatría, 3 (11), pp. 287-316, p. 313.

22 «Escritos de 28-11-1962 y 2-1-1963», A.H.P. Lugo, Fondos de Sanidad, Caja 27038. 
el área castellano-astur-leonesa la parálisis poliomielítica tuvo una incidencia del $0,5 \%$ en niños vacunados, incluso con las tres dosis ${ }^{23}$.

Las conclusiones, evidenciables desde el inicio de las «campañas» de vacunación Salk, parecían apuntar que era necesario cambiar la coordinación institucional en la organización de dichas campañas, las estrategias de propaganda y difusión entre la población y, como objetivo prioritario, garantizar la gratuidad para todos. Sin embargo, esta decisión no se tomó hasta 1963: cuando se inició la primera campaña nacional de vacunación oral Sabin, el balance de los años de vacunación Salk se saldaba, en las estadísticas oficiales, con 11.429 niños afectados y 1.301 fallecidos $^{24}$.

«IGUALDAD DE OPORTUNIDAD PARA DEFENDER LA SALUD»: LA CAMPAÑA DE VACUNACIÓN DEL SEGURO OBLIGATORIO DE ENFERMEDAD (1963)

El 10 de julio de 1962 se constituyó un nuevo Gobierno, con la continuidad de Camilo Alonso Vega al frente de Gobernación y con Jesús Romeo Gorría en Trabajo. Como «seuísta», éste se colocaba en un sector ahora minoritario procedente de Falange, con intereses afines, aunque sólo en algunos $\operatorname{aspectos}^{25}$, a los de los ascendentes tecnócratas del Opus Dei y con una visión bastante enfrentada al grupo de poder en que se hallaba Alonso Vega ${ }^{26}$. Proseguía, por tanto, la tradicional división de carteras entre militares católicos en Gobernación (a la que pertenecía la Dirección General de Sanidad) y falangistas en Trabajo (del que dependía el Seguro Obligatorio de Enfermedad, obra del Instituto Nacional de Previsión) ${ }^{27}$. La búsqueda de la nueva imagen de un Estado del bienestar en la economía desarrollista de los sesenta ${ }^{28}$ permi-

23 Ibid., p. 315

24 Los datos de morbilidad proceden de los publicados en la Revista de Sanidad e Higiene Pública, los de mortalidad del Instituto Nacional de Estadística.

25 Véase el enfrentamiento entre tecnócratas y falangistas en asuntos económicos, como los del sector olivarero y la posición de Romeo Gorría, pese a sus simpatías hacia el Opus Dei (SÁNCHEZ SOLER, M. (2001), Ricos por la patria, Barcelona, Plaza \& Janés Editores, pp. 161-163).

26 Tũ̃ón DE LARA, M. (1985), El poder y la oposición. En BIESCAS, J.A., TuÑón DE LARA, M., España bajo la dictadura franquista (1939-1975), Barcelona, Editorial Labor, pp. 165-431, pp. 297-302 (TUÑón DE LARA, M. (dir.), Historia de España, tomo X).

27 RODRÍGUEZ OCAÑA (2001), pp. 190-191.

28 García Delgado, J.L., JimÉneZ, J.C. (1996), La economía. En CARR, R. (coord.), La España de Franco (1939-1975), Madrid, Espasa-Calpe, I, pp. 445-511, pp. 475-481 (JOVER Zamora, J.M. (dir.), Historia de España Menéndez Pidal, tomo XLI). 
tió el intento de transformación del SOE mediante la Ley de Bases de la Seguridad Social de diciembre de $1963^{29}$. De este modo, en la maraña de la sanidad española en la que todos los ministerios llegaron a tener algún tipo de competencia sanitaria ${ }^{30}$, el Instituto Nacional de Previsión alcanzó una expansión que lo convertiría en eje principal de la política social franquista y centro de poder sanitario.

Es importante tener en cuenta este contexto para comprender algunos de los elementos más característicos de la campaña de vacunación antipoliomielítica iniciada por el SOE. La Orden del Ministerio de Trabajo, de 27 de diciembre de 1962, sobre campaña de vacunación antipoliomielítica masiva durante los meses de enero a junio de 1963, planteaba en sus cuatro artículos el desarrollo de un programa de vacunación para niños, hasta siete años, beneficiarios del SOE. La amplia cobertura en prensa permite reconstruir el desarrollo de la campaña: el 22 de enero se iniciaba la vacunación en Madrid, en seis ambulatorios del SOE que funcionaban mañana y tarde. Ese día y el siguiente se reunieron en la sede del Instituto Nacional de Previsión todos los Jefes Provinciales de Servicios Sanitarios, a quienes se les comunicaron los pormenores de la campaña y se les condujo a los ambulatorios que la estaban realizando ${ }^{31}$. Desde el 28 de enero se hizo extensiva a toda España con la expectativa de vacunar a dos millones de niños ${ }^{32}$.

La justificación que de esta campaña se aducía se podía encontrar en el preámbulo de la Orden:

«En su deseo de elevar el nivel de vida de los trabajadores españoles y de sus familiares, este Ministerio no puede olvidar la directa relación que aquél tiene con el nivel de salud y tiene que hacerse eco de la aspiración de aquéllos de proteger a sus hijos contra el riesgo de determinadas enfermedades. Una de las más graves es la poliomielitis, por el elevado porcentaje de secuelas incapacitantes que ocasiona. Las estadísticas de morbilidad para dicha enfermedad en España demuestran la in-

29 Moradiellos, E. (2000), La España de Franco (1939-1975) Política y sociedad, Madrid, Editorial Síntesis, p. 151. Para los datos de crecimiento del SOE en ésta década véanse Marset Campos, Sáez Gómez, Martínez Navarro (1995), p. 238; López PiÑero, J.M. (1978), La colectivización de la asistencia médica: una introducción histórica. En DE MiGUEL, J.M. (comp.), Planificación y reforma sanitaria, Madrid, Centro de Investigaciones Sociológicas, pp. 21-47, p. 41.

30 MuÑOZ MACHADO (1995), pp. 72-73.

31 PROA, 23-1-1963, p. 4; El Progreso, 29-1-1963, p. 8.

32 El Progreso, 29-1-1963, p. 2. 
cidencia de alrededor de dos mil casos anuales, de los que prácticamente la mitad se dan en hijos de trabajadores protegidos por el Seguro de Enfermedad» ${ }^{33}$.

Aunque más contenida en su retórica, esta introducción no desdice del espíritu falangista fundacional del SOE, para el que la asistencia prestada era concebida como concesión del vencedor más que como derecho de un trabajador que cotizaba ${ }^{34}$, aunque presentada desde el habitual discurso populista de la implantación de la justicia social merced a la revolución acaudillada por Franco, que integraba a las masas en la vida nacional atendiendo sus justas reivindicaciones ${ }^{35}$. Así queda plasmado en uno de los avisos publicitarios aparecidos en la prensa: «Igualdad de oportunidad para defender la salud. Esta es la consigna del Ministerio de Trabajo al Seguro de Enfermedad en la campaña de vacunación antipoliomielítica» ${ }^{36}$.

La propaganda en prensa se sustentó en varios pilares: la garantía de que la vacuna era aplicada por pediatras y la gratuidad (evitando matizar que sólo era tal para los escasos beneficiarios del SOE en aquellos momentos). Ilustran esta utilización la foto distribuida por CIFRA, en la que una enfermera aplica la vacuna a una niña bajo la supervisora mirada de uno de los mil Pediatras Consultores previstos por la Orden ${ }^{37}$. Respecto a la gratuidad como propaganda se hace evidente en la siguiente viñeta que focaliza la atención en un artículo rotulado con grandes caracteres «Está conjurado el espectro de la terrible poliomielitis». Debió darse por supuesto que los lectores sólo repararían en la imagen y el titular, pues el contenido del artículo hablaba del éxito en Alemania de la «vacuna de deglutir» ${ }^{38}$. Incluso aunque el lector se adentrase en la epidemiología germana de la polio, no era probable que observase la contradicción pues durante toda la campaña se silenció el tipo de vacuna que se estaba usando.

33 Boletín Oficial del Estado, $\mathrm{n}^{\circ} 1,1-1-1963$, pp. 5-6.

34 De Miguel (1979), pp. 25-27 y 33-54.

35 Molinero Ruiz, C. (2005), La captación de las masas. Política social y propaganda en el régimen franquista, Madrid, Cátedra, pp. 83-127.

36 El Progreso, 29-1-1963, p. 2.

37 PROA, 23-1-1963, p. 1.

38 Diario de León, 30-1-1963, p. 4. 


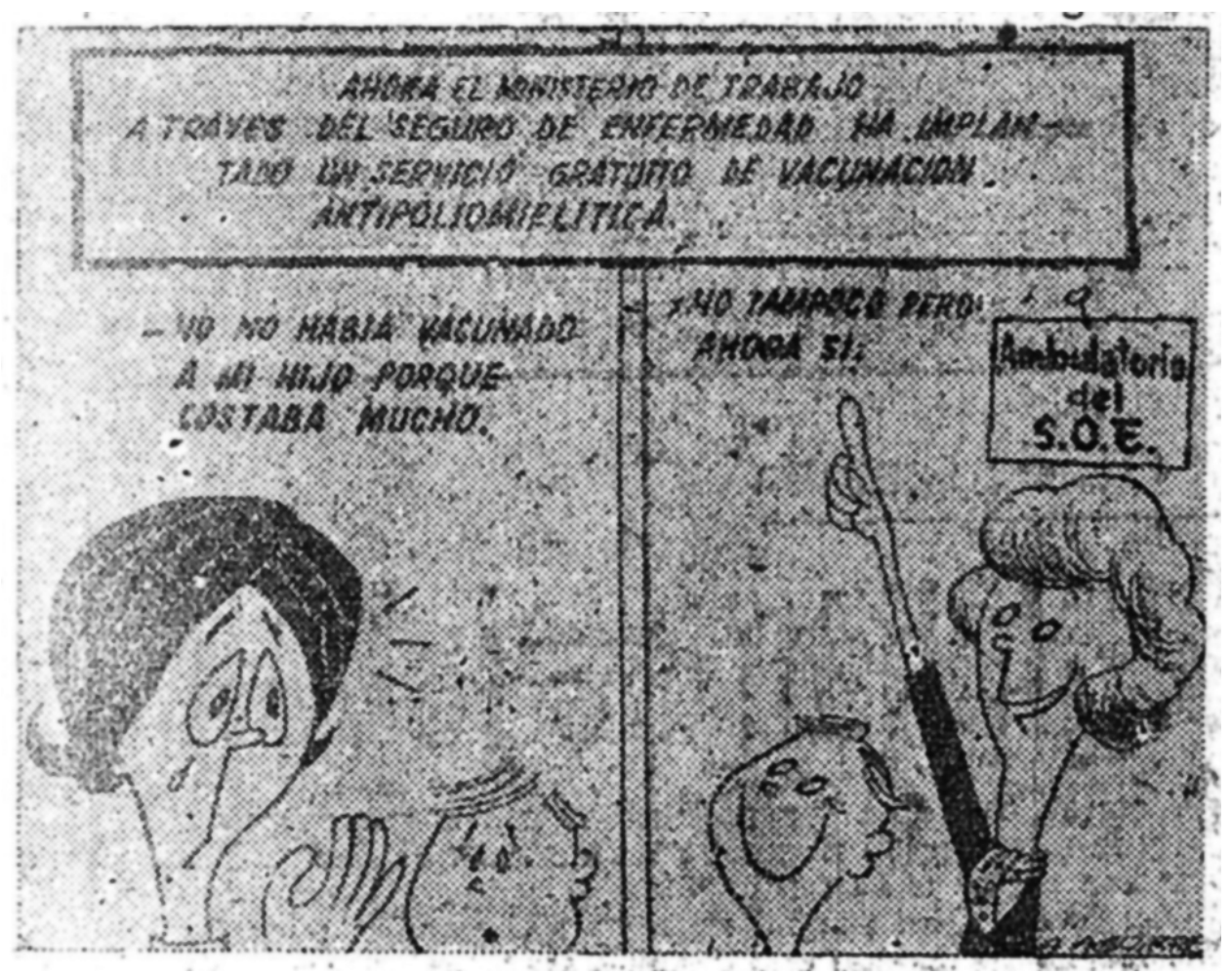

Ilustración 1. Viñetas publicitarias aparecidas en Diario de León, 30-1-1963, p. 4.

El mensaje de las viñetas era inequívoco: el SOE había hecho posible que la vacunación llegase gratuitamente a los trabajadores. Por tanto, campaña contra la polio, pero también campaña de imagen y estrategia de búsqueda de apoyo y captación de los trabajadores ante una Ley de Bases en ciernes con la que consolidar el proyecto de seguro y expandir sus competencias. La prensa transmitió cuáles eran las pretensiones del Instituto Nacional de Previsión en materia sanitaria, siendo la campaña de vacunación antipoliomielítica el inicio de una «política de implantar la medicina preventiva en el SOE» ${ }^{39}$.

El modelo de la «revolución sanitaria» falangista buscaba la unificación y colectivización de todos los servicios sanitarios, a través de un Seguro Nacional obligatorio y total. El Seguro Obligatorio de Enfermedad nació en 1944

39 PROA, 23-1-1963, p. 4. 
con estas pretensiones que han de enfrentarlo a los sectores de la Beneficencia y la DGS. Ya desde esos primeros momentos, ésta última reclamaba al SOE «que las campañas de tipo preventivo se realicen no para sustituirnos, sino para ayudarnos» ${ }^{40}$. El SOE actuó como freno para la DGS (absorbiendo muchas de sus funciones), que - con un presupuesto muy inferior al del SOE - fue perdiendo capacidad para desarrollar esas tradicionales competencias preventivas ${ }^{41}$.

En ese camino hacia unas funciones sanitarias cada vez más amplias, no era una de las menores la autonomía para negociar directamente con los laboratorios la adquisición de vacuna ${ }^{42}$, según determinaba la Orden de 27 de diciembre, según la cual «el Instituto Nacional de Previsión hará la adquisición de las dosis de vacunas necesarias para llevar a cabo la campaña mediante gestión directa ante la presentación de propuestas escritas» ${ }^{43}$. Poco tiempo debió quedar de plazo para la presentación de estas propuestas, pues la campaña se inició a las tres semanas de publicada la Orden y ya en esas fechas se reflejaba en prensa que «dada la magnitud de la campaña, la vacuna adquirida ha sido seleccionada entre las producidas por los mejores laboratorios del mundo dedicados a esta especialidad contra la poliomielitis $\gg{ }^{44}$. Una celeridad acorde con la rapidez con que la DGS intentó reivindicar su papel y frenar al SOE (ya en plena campaña de vacunación antipoliomielítica con vacuna Salk) mediante la Orden de 26 de enero.

40 Palanca, J.A. (1944), La Dirección General de Sanidad y el Seguro de Enfermedad, Ser, 34-35, p. 61 (citado por De Miguel (1979), pp. 49-50). El propio Palanca, Director General de Sanidad en esa primera época, hizo referencia a los ataques y estrategias usadas contra él por Falange (Palanca (1963), Medio siglo al Servicio de la Sanidad Pública, Madrid, Cultura Clásica y Moderna, pp. 153-154).

41 MuÑOz MACHAdo (1995), p. 82. Para conocer otro apunte de esos primeros enfrentamientos sobre competencias sanitarias, en este caso en lo que afectó a Florencio Pérez Gallardo, véase NÁJERA, R. (2006), Florencio Pérez Gallardo 1917-2006, Revista Española de Salud Pública, 80(5), pp. 605-608, pp. 605-606.

42 Hasta ese momento la DGS gestionaba las compras de vacuna Salk y su distribución, cobrando al SOE al precio de personas pudientes, es decir, 9 pesetas por dosis (A.H.P. Lugo, Fondos de Sanidad, Caja 27039).

43 Boletín Oficial del Estado, no 1, 1-1-1963, pp. 5-6.

44 Diario de León, 22-1-1963, p. 3. 
«NUNCA PARA EL ENSAYO DE LA VACUNA»: LA PREPARACIÓN DE LA CAMPAÑA PILOTO CON VACUNA(S) ORAL(ES) SABIN

La Orden de 27 de diciembre, la campaña en prensa y las declaraciones sobre competencias del Seguro de Enfermedad permiten comprender el título de la Orden de 26 de enero con que replicaba el Ministerio de Gobernación: «normas en cuanto a las obligaciones y facultades de la Dirección General de Sanidad en materia de Medicina Preventiva (vacunación antipoliomielítica)».

Se desprende de este título que la vacunación quedaba relegada a un segundo plano (y entre paréntesis) ante el debate crucial sobre a qué institución le correspondía organizar la prevención sanitaria en España. La introducción ya señalaba que la legislación en vigor hacía recaer las responsabilidades y atribuciones de la Medicina Preventiva en el Ministerio de la Gobernación, lo que incluía la vacunación antipoliomielítica. Tras recordar la reciente historia de la vacunación antipolio y el articulado de la Ley Fundacional del Seguro que exigía la autorización de la DGS en materia vacunal, pasaba a establecer, en su artículo tercero, que

«el Seguro de Enfermedad en la campaña de vacunación iniciada se somete a las siguientes normas y directrices: a) Facilitará la información necesaria para que la adquisición, recepción, conservación y distribución de las vacunas antipolio empleadas se conozcan por los Servicios técnicos de la Dirección General de Sanidad a los oportunos efectos ${ }^{45}$.

Todo el razonamiento previo sobre la conveniencia del uso de «la nueva vacuna antipoliomielítica con virus vivo, tipo Sabin, por vía bucal» se eludía al abordar la realidad de la campaña que ya estaba realizando el SOE, evitando especificar de qué tipo de vacuna se trataba. Pero lo mismo sucedía en la práctica con la propia DGS, que enviaba una circular a los Jefes Provinciales de Sanidad para que intensificasen la campaña de vacunación de 1962 entre los meses de febrero a abril de 1963, siendo su gratuidad la única, pero importante, diferencia respecto a la anterior ${ }^{46}$.

Un argumento relevante para que se produjese esta contradicción con lo expuesto en la Orden pudo ser la situación económica que se hubiese derivado de detener una campaña ya iniciada, con fuertes inversiones en vacunas y

45 Orden de 26 de enero de 1963 de Ministerio de la Gobernación (B.O.E., 30-1-1963, n ${ }^{\circ}$ 26, pp. 1649-50, p. 1650).

46 Boletín Oficial de la Provincia de Lugo, 5-2-1963, n 30, pp. 1-2. A.H.P. Lugo, Fondos de Sanidad, Caja 27039. 
una publicidad en todos los medios de comunicación por parte del $\mathrm{SOE}^{47}$. Los acuerdos efectuados con los laboratorios en la adquisición y comercialización de vacuna Salk debieron ser poderosos argumentos para no sólo no detener la campaña con Salk del SOE (sustituyéndola por Sabin), sino para que la DGS se sumase también hasta finales de abril al mismo tipo de vacuna. Si en 1958 la vacuna enviada por la DGS (a una provincia como Lugo) provenía de Lilly, Parke Davis, Vekar e Indiana, ésta última superaba en número de viales a las otras tres juntas y se convirtió en único suministrador hasta 1962-1963, en que la exclusividad pasó a ser de Landerlan (concesionario en España de los laboratorios Connaught canadienses). En cambio, para la misma provincia y en este último año, la vacuna adquirida por el INP fue del laboratorio Lilly ${ }^{48}$. Dos instituciones con dos intereses diferentes en negociar la adquisición de la misma vacuna.

Puesto que no parecía posible prescindir de la vacunación Salk (al menos hasta mediados de 1963), la aparición de la Orden resultaba prematura y evidenciaba así su intento de frenar al Instituto Nacional de Previsión, pues desde el propio texto, la Dirección General de Sanidad reconocía estar aún en una fase de dotar económicamente el establecimiento de laboratorios con función técnica de control de la vacunación ${ }^{49}$. Sin embargo, la falta de preparación para el inicio de la campaña no fue debida a la ausencia de estudios previos sobre la misma. Florencio Pérez Gallardo ${ }^{50}$, con sus colaboradores del Servicio de Virus de la Escuela Nacional de Sanidad, había realizado ya importantes estudios epidemiológicos sobre la poliomielitis en España que habían visto la luz en la Revista de Sanidad e Higiene Pública. Los estudios sobre morbilidad y mortalidad les habían permitido determinar que la letalidad era

47 En 1963 Movierecord produce para el Instituto Nacional de Previsión dos cortometrajes publicitarios de animación en los que no se hace alusión directa a la vacunación, pero sí rotulan sus últimos planos con «Campaña contra la polio I.N.P.». (A.G.A., Fondos (3)121, Censuras Cinematográficas, expedientes 27704 y 27718). Otras producciones animadas se llevaron a cabo en los siguientes años. Para su análisis y el del uso de la imagen cinematográfica en las campañas antipolio españolas véase BALLESTER AÑón, R. (2008), Imágenes de la vulnerabilidad: las fuentes fílmicas de la poliomielitis en España. En ORTIZ GóMEZ, T. et al. (coord.), La experiencia de enfermar en perspectiva histórica, Granada, Universidad de Granada, 2008, pp. 335-339, p. 338.

48 A.H.P. Lugo, Fondos de Sanidad, Caja 27039.

49 Orden de 26 de enero de 1963 de Ministerio de la Gobernación (B.O.E., 30-1-1963, no 26, pp. 1649-50, p. 1650)

50 Sobre Florencio Pérez Gallardo véase la necrológica de NÁJERA (2006), pp. 605-608 y TUELLS HERNÁNDEZ (2008), pp. 321-324. 
del $8,95 \%$, que el $87 \%$ de los casos paralíticos se producían antes de los cinco años (porcentaje mayor que en otros países) y que la estacionalidad preferente era de julio a octubre. A través de importantes encuestas serológicas (con 5.119 muestras de suero llegadas de toda España) determinaron la distribución de los tres tipos del virus y constataron que en una campaña habría que vacunar a todos los niños hasta los cinco años. A tal fin, la elección de las cepas Sabin también parecía la más lógica si se pretendía una erradicación gracias a la creación de una resistencia intestinal y venía avalada por la OMS y experiencias de campañas en numerosos países ${ }^{51}$.

Aunque es innegable que la complejidad de desarrollar una campaña exigía realizar unas labores organizativas previas, los meses transcurrían desde la aparición de la Orden sin que se anunciase la vacunación Sabin. El 19 de marzo el diario Pueblo pedía aclaraciones a las autoridades sanitarias sobre este particular, obteniendo como respuesta un comunicado en prensa que ratificaba las causas de la dilación ya esgrimidas en la Orden ${ }^{52}$. Adaptaciones necesarias, pero de más fácil solución que los obstáculos que planteaban las «familias» políticas y los grupos de poder sanitario, especialmente el de los pediatras liderados por Bosch Marín y afines al SOE que ya estaban llevando a cabo la campaña de vacunación con Salk ${ }^{53}$. Esta falta de entendimiento y colaboración entre DGS y pediatras, mediada por la posición respecto al SOE, había estado presente en la lucha contra la poliomielitis antes del anuncio de la vacunación oral. Cuando la Sociedad Castellano-Astur-Leonesa de Pediatría dedicó en 1962 unas sesiones monográficas al tema de la poliomielitis, el citado catedrático de pediatría de Salamanca, Ernesto Sánchez-Villares, presentó junto a Álvarez Suárez los resultados de una encuesta sobre aspectos epidemiológicos y clínicos: de las diez provincias, la única Jefatura Provincial de Sanidad que colaboró en ella fue la de Palencia, a cargo de Martín Prado ${ }^{54}$.

El debate decisivo con los pediatras se entabló en marzo de 1963, en una mesa redonda de la Sociedad de Pediatría de Madrid, que tras varias reuniones

51 Con gran profusión de detalles puede encontrarse el relato pormenorizado en PÉREZ Gallardo, F., Vega Villalonga, J., Pérez Mel, J., López Villalba, L., Nájera MoRRONDO, R. (1964), Campaña Piloto de Vacunación antipoliomielítica por vía oral, Revista de Sanidad e Higiene Pública, 38(7-9), pp. 443-501.

52 Pérez Gallardo, Vega Villalonga, Pérez Mel, López Villalba, NáJera MoRRONDO (1964), p. 480.

53 Bosch Marín fue uno de los más destacados promotores del SOE. Véase Bosch MARÍN, J. (1960), Lo que dijo un médico español del Seguro de Enfermedad. Discurso del Doctor Juan Bosch Marín en la Asamblea de Médicos del S.O.E. Día 5 de diciembre de 1958, Madrid.

54 SÁNChez Villares, Álvarez SuÁREZ (1962), p. 289. 
llegó, en su sesión del día 18 de abril, a unas conclusiones que, con prudencia y ambigüedad, consideraban igualmente válidas ambas vacunas, aunque

«por sus características especiales de economía y de empleo fácil, es aconsejable la vacunación de tipo Sabin para efectuar una vacunación masiva de la población más receptiva y de desarraigo de la enfermedad» ${ }^{55}$.

Pero, hasta ese espaldarazo de la pediatría, Florencio Pérez Gallardo y su equipo tuvieron que desarrollar una estrategia para conseguir el auspicio de las instituciones, claramente expuesta por Tuells a partir de los testimonios de los propios protagonistas: una vez descartada la posibilidad de fabricación nacional de la vacuna, el apoyo del recién nombrado Secretario General de Sanidad, José Manuel Romay Beccaría, a quien Pérez Gallardo garantizó el éxito de la campaña, supuso un paso decisivo ${ }^{56}$.

La otra baza fue la organización de una visita a España de Albert Sabin, a principios de febrero, y su utilización mediática. Las provocaciones procedieron de ambas partes y los dos bandos emplearon a sus más significativas figuras. Recordemos que la campaña de vacunación Salk del SOE estaba en marcha y que fue el lunes 4 de febrero cuando se inició en los ambulatorios de muchas capitales de provincia ${ }^{57}$. Al día siguiente, 5 de febrero, Bosch Marín daba su conferencia sobre «La poliomielitis en Europa en 1962», en la Real Academia Nacional de Medicina y, aunque sea recordada como "panegírico de la vacuna Salk» ${ }^{58}$, el texto muestra un examen de las diferentes, cambiantes y discutidas experiencias vacunales en Europa (incluida Rusia) con Salk y con Sabin $^{59}$, un reconocimiento de la efectividad de ambas y una preferencia por la Sabin para la erradicación. Bien es cierto que en su presentación subyace el intento de mostrar la homogeneidad en la diversidad, la validez de las estrategias vacunales del SOE y una defensa de no interrumpir una campaña con

55 Pérez Gallardo, Vega Villalonga, Pérez Mel, López Villalba, Nájera MoRRONDO (1964), p. 480.

56 TuElls HeRnÁNDEZ (2008), p. 323.

57 PROA, 3-2-1963, p. 4.

58 Referido por Fernando Ruiz Falcó en Tuells HeRnández (2008), p. 323.

59 Desde la aparición de la vacuna Salk las discusiones en los foros científicos y las diferentes políticas de vacunación adoptadas mundialmente muestran que la discusión en España estaba fundamentada por ambas partes con numerosos argumentos en pro y en contra para ambos tipos de vacunas (AITKEN (2004), pp. 195-207; GOULD (1995), pp. 159-187; LINDNER, Blume, (2006), pp. 425-446). 
Salk en la que habían invertido tanto esfuerzo, para lo que citaba una sentencia irlandesa «no cambiemos de bicicleta cuando bajamos una pendiente» ${ }^{60}$.

Poco convencida de ese descenso, la Dirección General de Sanidad celebró al día siguiente, 6 de febrero, la primera conferencia de Albert Sabin en el Consejo Superior de Investigaciones Científicas ${ }^{61}$. Toda la cúpula de Gobernación respaldó el acto, e incluso el Presidente de la Academia de Medicina, pero la prensa no ofreció información sobre si estuvieron presentes los responsables del Instituto Nacional de Previsión y $\mathrm{SOE}^{62}$. En sus tres días de estancia en Madrid, Sabin fue llevado a dar conferencias y ruedas de prensa. En éstas estuvieron presentes los medios de comunicación, «los periodistas de todos los diarios, agencias, emisoras y televisión de Madrid $\rangle^{63}$, aunque la cobertura fue bastante desigual, según los periódicos, en comparación con la prestada a Bosch $^{64}$. Gerardo Clavero, Director de la Escuela Nacional de Sanidad, aprovechó para anunciar que «en cosa de dos meses la Dirección General de Sanidad va a comenzar estas campañas masivas, antes de que llegue el calor» ${ }^{65}$.

$\mathrm{Ni}$ fueron dos meses ni la campaña tuvo carácter nacional, pues hasta el mes de mayo no se inició una campaña piloto de vacunación en las provincias de León y Lugo. Pérez Gallardo en su memoria de la misma la presentaba como parte de un bien estudiado proceso:

«[...] ante la posibilidad científica y administrativa de empezar la vacunación, se comenzó por pensar en la realización de una campaña piloto de donde pudieran emanar las enseñanzas prácticas necesarias para posteriormente llevar a cabo una campaña nacional $[. .$.$] estaba plenamente justificada por cuanto no se habían realizado pre-$ viamente en España trabajos de este tipo [...] de breve duración, de desarrollo intensivo y de gran magnitud [...] Conviene que señalemos que se trataba de una fase piloto en el sentido meramente administrativo y de organización, y nunca para el ensayo de la vacuna, para conocer sus posibilidades y contraindicaciones [...].»

60 Bosch Marín, J. (1963), La poliomielitis en Europa en 1962, Anales de la Real Academia Nacional de Medicina, 80, pp. 77-104. Otra interpretación complementaria del contenido de este discurso en BALLESTER (2008).

61 El texto completo de la conferencia apareció publicado en Pérez GALlARDO, F., VEGA VILLALONGA, PÉrEZ MEL, LÓPEZ VillalBA, NÁJERA MORRONDO (1964), pp. 496-501.

62 PROA, 7-2-1963, p. 4.

63 PROA, 9-2-1963, p. 4.

64 Porras Gallo, M.I., Báguena Cervellera, M.J. (2008), La poliomielitis en la España franquista a través de la prensa general (1940-1975). En ORTIZ GóMEZ, T. et al. (coord.), La experiencia de enfermar en perspectiva histórica, Granada, Universidad de Granada, pp. 325-329, pp. 327-328.

65 PROA, 9-2-1963, p. 4. 
La misma memoria, el reflejo de la campaña en prensa y el testimonio de algunos médicos muestran algunas divergencias sobre las que reflexionar. Lo más evidente es que se ocultó a la población, e incluso a los médicos, que se trataba de una fase piloto, pues fue presentada ya como campaña nacional. Con diferentes estrategias en las dos provincias elegidas, El Progreso de Lugo fue el único que apuntó cierto carácter diferencial de la provincia: «Al mismo tiempo que en Lugo — una de las primeras provincias que desarrollará este programa- se llevará a cabo en León y otras poblaciones» ${ }^{66}$. Si la decisión de eludir la presentación de la vacunación como un ensayo podía ser una estrategia para evitar los temores de la población (en quienes había dejado huella la interesada propagación de los errores con la Salk) ${ }^{67}$, la escasa información a los médicos, especialmente en los entornos rurales, no parecía justificada: ninguno de los médicos entrevistados o consultados eran conscientes de haber participado en una campaña piloto ${ }^{68}$. Igualmente, parece difícil comprender que si se trataba de un ensayo meramente administrativo no sólo no se respetasen las mismas épocas del año para la aplicación de la vacuna (en León se produjeron las dos fases seguidas, con seis semanas entre ambas, desde mayo a julio; en Lugo, hubo una primera fase de mayo a junio y una segunda de octubre a noviembre), sino que las vacunas fuesen diferentes, no sólo en los laboratorios, sino también en su composición: en tanto que León vacunaba en sus dos fases con vacuna trivalente (tipos I, II y III en la misma) y en dos grupos con diferentes concentraciones ${ }^{69}$; en Lugo se vacunó en la primera fase con monovalente tipo I y en la segunda con bivalente II y III ${ }^{70}$.

66 El Progreso, 3-5-1963, p. 8.

67 MuÑOZ SiNGi (2007).

68 No sólo Antonio Mallo y Antonio Silván mostraron este desconocimiento, sino también los otros tres médicos a los que quisimos entrevistar, para quienes las vacunaciones habían supuesto una actividad rutinaria sin particularidad alguna. De hecho, el folleto publicitario que posteriormente se distribuyó a los médicos para la primera campaña nacional lo apuntaba eludiendo el adjetivo «piloto»: «[...] hace unos meses hemos realizado, en las provincias de Lugo y León, una campaña de vacunación totalmente gratuita, a base de la vacuna más eficaz y de mayor facilidad en su administración: la vacuna de Sabin» (S.A. (1963), Estado actual y fundamentos de la vacunación contra la poliomielitis, Madrid, Dirección General de Sanidad, 30 pp., pp. 3-4).

69 Pérez Gallardo, Vega Villalonga, Pérez Mel, López Villalba, Nájera MoRRONDO (1964), p. 459.

70 Pérez Gallardo, Vega Villalonga, Pérez Mel, López Villalba, Nájera MoRRONDO (1964), p. 471. 
Es sorprendente este uso de una vacuna Sabin trivalente cuando sólo tenemos noticias de su uso parcial (como ensayo) en Rusia en $1960^{71}$. Su desarrollo, ensayos y aprobación en Canadá por los laboratorios Connaught (uno de los más importantes en la fabricación de vacuna Salk y sus diferentes combinaciones con DTP) se produjo en marzo de $1962^{72}$, siendo el primer país que la aprobaba $^{73}$. Los laboratorios Connaught fueron los grandes exportadores de la vacuna Sabin, dada la reticencia en Estados Unidos, no sólo por motivos políticos ante la «vacuna rusa», sino también por las dificultades para realizar ensayos en una población ampliamente inmunizada por el uso masivo de la Salk. No obstante, en 1962 Estados Unidos autorizaba los tres tipos de vacuna Sabin, pero hasta agosto de 1963 no aprobaba la fabricación de «la nueva vacuna trivalente Orimune» del laboratorio Lederle. Esta información aparecía el día cinco de agosto en el Diario de León, provincia en la que, sin publicidad al respecto ni conocimiento de la población, se había realizado al completo una campaña piloto con esa innovadora vacuna trivalente ${ }^{74}$.

En un breve artículo, casi apéndice a la memoria de la campaña piloto, Pérez Gallardo reconocía que «se pretendió con ella extraer una serie de experiencias prácticas de todo orden». Sin embargo, pocas líneas después, ponía de manifiesto indirectamente que el interés del ensayo («en estrecha relación con el laboratorio») radicaba en la comparación entre la administración de la monovalente en Lugo y la trivalente en León, pues sólo hacía referencia al período mayo-julio, olvidando la segunda fase con bivalente en Lugo a partir de octubre ${ }^{75}$. Las «experiencias prácticas» fueron satisfactorias y la trivalente se empleó en abril de 1964, en la segunda fase de la Primera Campaña Nacional, siendo la primera fase con monovalente tipo $\mathrm{I}^{76}$.

71 De lo cual informó Bosch Marín en su discurso en la Academia: se usaron vacunas con poliovirus vivos administradas en grageas de tipo monovalentes, bivalentes I y III y trivalentes I, II y III (BOSCH MARÍN (1963), p. 96).

72 Barreto, VAn Exan, RutTy (2006), p. 96.

73 RutTy, C.J. (1995), Poliomyelitis in Canada, 1927-1962 [tesis], Toronto, University of Toronto, p. 356 (Citado por AITKEN (2004), p. 200).

74 Diario de León, 5-8-1963, p. 8.

75 Pérez Gallardo, Valenciano Clavel, Gabriel y Galán (1964), p. 502.

76 MEZQuita LóPEZ, M. (1965), Evaluación de resultados de la primera campaña de vacunación contra la poliomielitis por vía oral en España, Madrid, Ministerio de la Gobernación Dirección General de Sanidad, p. 21; PÉrez Gallardo, F., VAlenciano Clavel, L., Gabriel Y GALÁN, J. (1965), Resultados de la Campaña nacional de vacunación antipoliomielítica por vía oral en España, Revista de Sanidad e Higiene Pública, 39(10), pp. 537-561, p. 540. 

(1963)

Desde la hipótesis de que la campaña piloto fue concebida como ensayo de la nueva vacuna trivalente, tenemos que reconsiderar las explicaciones dadas a la elección de las provincias de León y Lugo. La memoria de la campaña basaba la designación en la epidemiología, en que sus capitales de provincia no fuesen las más populosas, en que tuviesen un clima frío, variedad geográfica (orográfica y poblacional), fuesen limítrofes para que se pudiese intercambiar la información fácilmente y contasen con autoridades sanitarias provinciales especialmente interesadas en el problema ${ }^{77}$.

Los elementos geográficos ofrecían indudablemente en las provincias elegidas un buen modelo para testar todas las posibles dificultades administrativas y de organización. Respecto a la epidemiología, tanto Lugo como León se encontraban entre las provincias españolas con menores tasas de morbilidad (pese a la epidemia de 1958 , que afectó especialmente a Lugo) ${ }^{78}$ y se habían realizado en ellas estudios serológicos previos, aunque con escasa participación ${ }^{79}$. Sin embargo, parece un elemento de mayor peso la personalidad de quienes se encontraban en las Jefaturas en esos momentos, especialmente en la de León, que es donde se iba a aplicar la trivalente. José Vega Villalonga era militar (médico de la Armada), ocupaba el puesto de Inspector Provincial de Sanidad desde 1925 y había demostrado su efectividad en la organización de campañas de vacunación en la antituberculosa con BCG de los años treinta ${ }^{80}$. Respecto a José Pérez Mel, Jefe Provincial de Sanidad de Lugo, tenía también una larga experiencia y buena relación con Pérez Gallardo, con quien compartía la convicción de la necesidad de introducir la vacunación con Sabin y hacía cinco años había iniciado la búsqueda de «un poblado de Piedrafita del Cebrero que resultase adecuado para la experiencia en el caso de que la Superioridad la autorizara ${ }^{81}$.

77 Pérez Gallardo, Vega Villalonga, Pérez Mel, LóPez Villalba, NáJera MoRRONDO (1964), pp. 449-450 y 452.

78 Pérez Gallardo, F., NÁjera Morrondo, E., Ruiz Falcó, F. (1963), Epidemiología de la poliomielitis en España (Estudio de la morbilidad y mortalidad durante los años 19311935 y 1940-1962), Revista de Sanidad e Higiene Pública, 37(11-12), pp. 454-470, p. 458.

79 PÉrez Gallardo, F. (1962), Epidemiología de la poliomielitis en España (Encuesta serológica para la determinación de los anticuerpos antipoliomielíticos en la población española), Revista de Sanidad e Higiene Pública, 36, pp. 501-518.

80 Fernández Arienza, J. (1994), Crónica de la Medicina en León 1900-1993, León, Colegio Oficial de Médicos de León, pp. 191-192.

81 «Memoria de actividades - Año de 1963. Jefatura Provincial de Sanidad de Lugo», A.H.P. Lugo, Fondos de Sanidad, Caja 27167. 
La campaña comenzó en León el día 30 de abril, con una conferencia de Florencio Pérez Gallardo en el salón de actos de la Jefatura Provincial de Sanidad, presentado ya como Director de la Campaña Nacional de Vacunación Antipoliomielítica. Había viajado con un equipo de expertos entre los que se encontraban Valenciano y López Villalba. PROA destacó que Pérez Gallardo era experto de la OMS en poliomielitis ${ }^{82}$. Esta primera conferencia había sido anunciada con una entrevista aparecida el mismo día, en la que se plasmaron los elementos más característicos que tanto el entrevistado como la Dirección General de Sanidad querían difundir en la campaña mediática: los de tipo divulgativo-pedagógico (epidemiología de la polio, previsiones de desarrollo epidémico, tipos de vacunas, ventajas de la vacuna Sabin y, especialmente, la necesidad de vacunar con Sabin a quienes habían sido vacunados con Salk), los de tipo informativo sobre el desarrollo de la campaña (grupo de edad a vacunar, inicio de la campaña, lugares y gratuidad) y los de defensa de la vacunación como competencia de la DGS ${ }^{83}$.

El dos de mayo Pérez Gallardo se encontraba ya en Lugo, acompañado por López Villalba y Ruiz Falcó, para pronunciar otra conferencia, en esta ocasión en el Instituto Provincial de Sanidad. Contaba con el respaldo de la Jefatura Provincial de Sanidad y del Colegio Oficial de Médicos ${ }^{84}$. La prensa dio cuenta de los asistentes más representativos: María Isabel Gayoso (Delegada de la Sección Femenina), Rego Martínez (Presidente de la Diputación) y Santín Díaz (Delegado de Información y Turismo). La ausencia de los representantes del INP y SOE, al igual que en León, puede leerse entre líneas ${ }^{85}$.

La vacunación comenzó en León capital el 14 de mayo con la supervisión directa de Rafael Nájera: un artículo en Diario de León informaba de ella publicando por primera vez la imagen del cartel que se usó en la campaña nacional ${ }^{86}$. En Ponferrada (adonde Pérez Gallardo también llegó para dar su conferencia) ${ }^{87}$ se vacunaron 5000 niños en tan sólo dos días, 21 y 22 de mayo, en el Centro Secundario de Higiene ${ }^{88}$. El equipo vacunador (que se desplazó por la provincia desde el 3 de junio) utilizó estos centros o, generalmente, las escuelas tanto por la falta de consultorios como por la labor de propaganda realizada por los maestros.

\footnotetext{
82 PROA, 1-5-1963, p. 3.

83 PROA, 30-4-1963, p. 3.

84 El Progreso, 2-5-1963, p. 3.

85 El Progreso, 3-5-1963, p. 3.

86 Diario de León, 14-5-1963, p. 5.

87 PROA, 15-5-1963, p. 7.

88 PROA, 23-5-1963, p. 8.
} 
En este itinerario por los diferentes pueblos, la presencia de Vega Villalonga ha eclipsado en la memoria de los médicos al resto del equipo y sólo recuerdan la llegada del Jefe Provincial de Sanidad y las enfermeras, en un grupo de cinco o seis personas del que desconocen si alguien venía de Madrid ${ }^{89}$ :

«Porque la primera vacunación que hubo de la polio [...] pues fue el Jefe Provincial de Sanidad, fue don José Vega Villalonga, con, en fin, con todas las enfermeras y con todo aquello... fue un... un espectáculo» ${ }^{90}$.

Prensa y memorias nos indican que esas enfermeras eran en ocasiones cumplidoras del Servicio Social en Sección Femenina. Octavio Aparicio, uno de los primeros divulgadores en las campañas contra la polio en $Y a$, en sus frecuentes artículos en Teresa (revista de la Sección Femenina) ${ }^{91}$, dio una muy detallada crónica de la campaña piloto, excepcional en las revistas de la época, laudatoria de la labor desarrollada ${ }^{92}$.

Mientras, en León capital se siguió vacunando hasta el 23 de junio con la primera dosis ${ }^{93}$, en el Instituto Provincial de Sanidad, único sitio habilitado a tal fin. Manuel Valdés, periodista del diario del Movimiento, insertó un párrafo sobre este particular:

«Sugeríamos a los doctores la posible conveniencia de llevar a cabo la vacunación en algún otro centro, tal como en los nuevos grupos escolares, en el Dispensario de la Cruz Roja, y en algún otro lugar adecuado para ello» ${ }^{94}$.

Es significativo que no se mencione tampoco en esta ocasión el ambulatorio del SOE, donde en esos momentos se estaba vacunando con Salk. Y también lo es la centralización y control ejercidos por Vega en el proceso, que contrasta con la flexibilidad con que se llevaron a efecto los períodos de vacunación, prolongada en León capital hasta el día 23 de junio, momento en

89 Testimonios de Antonio Mallo y Antonio Silván.

90 Testimonio de Antonio Silván.

91 PitA, J.R., Rodríguez SÁnchez, J.A. (2008), Actitudes ante la polio en España y Portugal: estudio comparativo. En ORTIZ GómEZ, T. et al. (coord.), La experiencia de enfermar en perspectiva histórica, Granada, Universidad de Granada, pp. 331-334, p. 333.

92 APARICIO, O. (1963), Las mujeres españolas, en la lucha contra la parálisis infantil, Teresa, 116 (agosto), pp. 40-41.

93 Diario de León, 18-6-1963, p. 2.

94 PROA, 15-5-1963, p. 3. 
que concluyó en toda la provincia, para volver a reanudarse el 2 de julio como supuesta segunda fase ${ }^{95}$.

La campaña en Lugo ofreció remarcables diferencias respecto a la de León, no sólo justificables, tal y como figura en la memoria de la campaña piloto, por las condiciones geográficas y la diseminación de la población. Consideramos que los dos factores principales que influyeron fueron la diferente visión sobre la gestión sanitaria de Pérez Mel respecto a Vega Villalonga y, especialmente, el tratarse de una campaña concebida realmente en dos fases, pues iban a usar en la primera una monovalente tipo I y en la segunda una bivalente con los tipos II y III, lo que obligaba a conseguir la misma participación en ambas fases o, al menos, que en ambas fuese superior al $80 \%$.

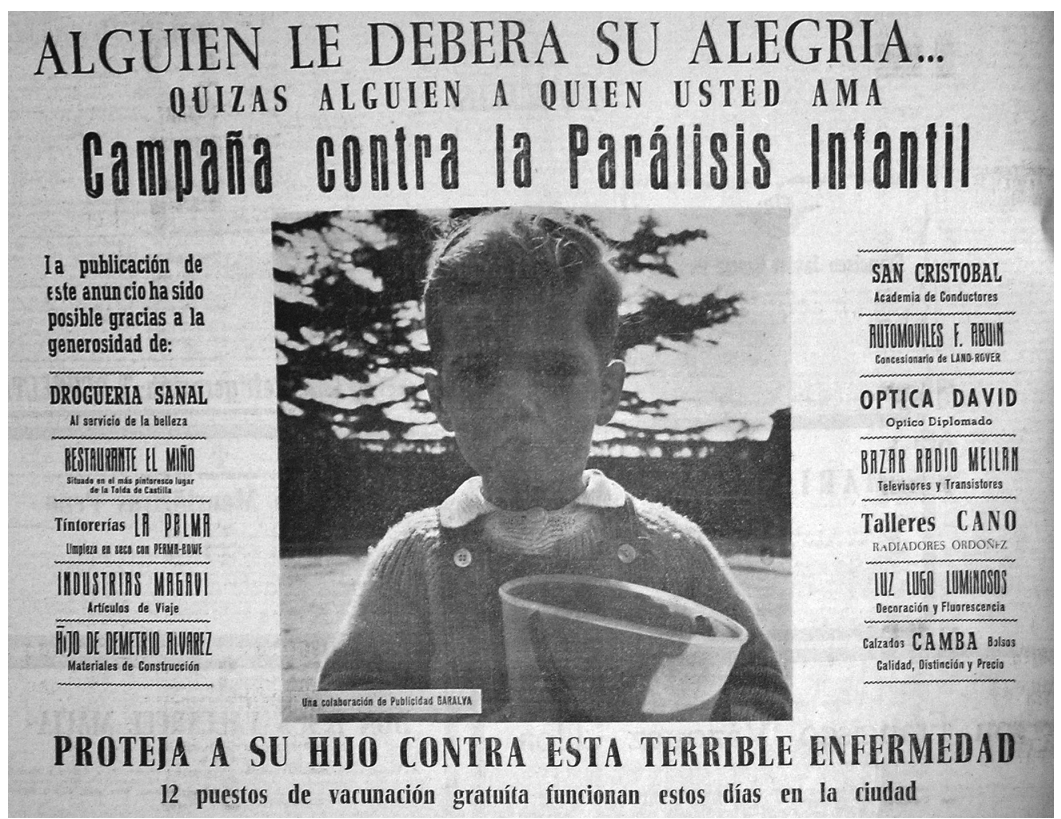

Ilustración 2. Anuncio aparecido en El Progreso, 26-5-1963, p. 6.

95 Diario de León, 18-6-1963, p. 2. Estas fechas que aparecieron en prensa no coinciden con las de la memoria de la campaña piloto, donde se hace constar que fueron del 14 de mayo al 21 de junio y del 13 de julio al 24 de agosto. El artículo aparecido en Diario de León, 9-71963 , p. 4, da prueba de que no fue así, pues se trata de una reconvención a los padres debido a la poca asistencia en la semana que llevaban de segunda fase de vacunación. 
Esa diferencia de concepción de la campaña por parte de Pérez Mel se observa en el papel que otorgó a los medios de comunicación, el mayor lugar ocupado por la divulgación y la utilización de los avisos (brevísimos sueltos en los que se realizaba una reflexión sobre la polio y la vacunación con el fin de concienciar y promover la participación). Estos avisos serían durante la posterior campaña nacional uno de los elementos más persistentes en toda la prensa del país ${ }^{96}$. Desde la aparición el día 2 de mayo de la entrevista a Pérez Gallardo, no cesaron las noticias sobre poliomielitis y la inminente campaña. Dio comienzo el 16 de mayo en la provincia, llegando a Lugo los días 24 y 25 , para continuar en las parroquias los días 27 y 29 y mantenerse en la capital hasta el 12 de junio. Las fechas claves fueron las del comienzo de la vacunación en la capital: desde el 21 al 31 de mayo, El Progreso ofreció una continua información, culminando el domingo 26 de mayo, víspera del inicio de la vacunación en las parroquias y momento de evaluación triunfal de los primeros resultados. Los 4.257 niños vacunados en Lugo capital en dos días fueron considerados un rotundo éxito que sirvió de estímulo a los vecinos de las parroquias para acudir. Un gran anuncio que ocupaba la mitad inferior de la página sexta, ponía de manifiesto, a través de dos columnas de empresas colaboradoras, los apoyos buscados por Pérez Mel en la sociedad lucense.

La segunda fase también contó con una intensa difusión en prensa con artículos y numerosos avisos, aunque no tanto como en la primera fase, conscientes de que aquí se trataba de completar la inmunización de la población frente a los tipos II y III del virus. La vacunación comenzó en esta ocasión por los municipios el día 22 de octubre, para continuar por las parroquias ${ }^{97} \mathrm{e}$ iniciarse en Lugo capital el día 31 y prorrogarse hasta finales de noviembre en el Instituto Provincial de Sanidad ${ }^{98}$, si bien Pérez Mel dio por concluida la campaña el día 5 de noviembre ${ }^{99}$.

Los apoyos sociales y políticos fueron necesarios para Pérez Mel en la pequeña batalla local, microcosmos de la nacional, que mantenía con Gómez Silva, Inspector de Servicios Sanitarios del SOE de Lugo. Recordemos que el SOE estaba realizando de forma paralela una campaña de vacunación gratuita para sus afiliados con vacuna Salk, de enero a junio. Sin embargo, en Lugo la campaña se mantuvo durante todo el año y no colaboraron en la campaña

96 MuÑOZ SINGI (2007).

97 El Progreso, 23-10-1963, p. 3; 27-10-1963, pp. 1 у 7.

98 El Progreso, 13-11-1963, p. 3.

99 Pérez Gallardo, Vega Villalonga, Pérez Mel, López Villalba, Nájera MoRRONDO (1964), p. 471. 
Sabin, ni tan siquiera en el inicio de la campaña nacional, según se desprende de un oficio de Gómez Silva, fechado el dos de diciembre de $1963^{100}$. La falta de colaboración y de asunción de la autoridad de la Jefatura Provincial en materia preventiva ${ }^{101}$ llegó a convertirse en decididas actuaciones contra la campaña piloto, según informó Pérez Mel al Gobernador Civil:

«[...] el actual Inspector Sr. Gómez Silva que es, además, la misma persona que, no hace mucho tiempo, intentó desacreditar la Campaña Antipolio del Ministerio de Gobernación con informaciones y con propaganda verbal subrepticia y tendenciosa. La Superioridad decidirá sobre esto lo que a su juicio sea mas conveniente ${ }^{102}$.

Otra de las diferencias notables con la campaña realizada en León residió en la búsqueda de participación de los médicos titulares y el acercamiento de la vacunación a los habitantes multiplicando los lugares en que se efectuaba, como se ejemplifica en Lugo capital, donde se llevó a cabo en las escuelas, la Casa Consistorial, el Instituto de Higiene, la Casa de Socorro - Hospital Provincial- y el Centro de Alimentación Infantil ${ }^{103}$. Recordemos que en la provincia de León, el recurso a las escuelas sólo existió en pueblos sin consultorios médicos y que en León capital se limitó al Instituto Provincial de Sanidad.

Los resultados de la campaña piloto fueron de 71.228 niños vacunados en toda la provincia de León durante la primera fase, más del $90 \%$ del total de la población susceptible, mientras que la segunda dosis sólo fue administrada a 52.241 niños ${ }^{104}$. Esta última cifra se publicó exclusivamente en la literatura

100 A.H.P. Lugo, Fondos de Sanidad, Caja 27042.

101 Pérez Mel informaba al Gobernador Civil de la imposibilidad de realizar un control de los organismos sanitarios dependientes del Ministerio de Trabajo («Memoria de actividades Año de 1963. Jefatura Provincial de Sanidad de Lugo», A.H.P. Lugo, Fondos de Sanidad, Caja 27167). Esta autonomía, les llevó a no informar sobre las vacunaciones que llevaban a cabo y a que tuviese que ser reclamada la información desde la Inspección General de Epidemiología y Estadística de la Dirección General de Sanidad (A.H.P. Lugo, Fondos de Sanidad, Caja 27042).

102 «Memoria de actividades - Año de 1963. Jefatura Provincial de Sanidad de Lugo», A.H.P. Lugo, Fondos de Sanidad, Caja 27167.

103 El Progreso, 21-5-1963, p. 2.

104 Pérez Gallardo, Vega Villalonga, Pérez Mel, López Villalba, NáJera MoRRONDO (1964), p. 462. Existe disparidad entre estas cifras y las que iban siendo anunciadas en prensa: el 18 de junio, el comunicado de la Jefatura Provincial de Sanidad (en que se anunciaba la finalización de la primera fase en toda la provincia el día 23 y el inicio de la segunda el dos de julio) daba las cifras de un total de 49.476 niños vacunados, entre León (8.113) y el resto de la provincia (41.363), lo que suponía un 90\% (Diario de León, 18-6-1963, p. 2). 
médica dado que suponía un exiguo $66 \%$, muy lejos del $80 \%$ pedido por Sabin para la erradicación ${ }^{105}$. Aunque en partidos como Riaño las vacunaciones bajaron de 3.183 a 1.366, la interpretación que se hizo de los resultados fue de éxito total. Conscientes los promotores de que se había vacunado en ambas ocasiones con trivalente, el porcentaje alcanzado en la primera fase era suficientemente satisfactorio y explica el descenso en la propaganda durante la segunda fase, de la que sólo hemos encontrado cinco breves noticias en los dos periódicos leoneses ${ }^{106}$.

En Lugo, como hemos expuesto, el desarrollo fue bien distinto y, puesto que la primera fase era con monovalente tipo I y la segunda fase con bivalente de los tipos II y III, había que garantizar en ambas ocasiones una participación superior al $80 \%$. En la primera fase fueron 48.666 los vacunados y en la segunda 41.889, lo que, atendiendo a los cálculos aproximativos de Pérez Mel sobre una población susceptible en torno a los 50.000 niños, supondría un $97,33 \%$ y un $83,77 \%$, respectivamente. Los medios de comunicación sólo recogieron el porcentaje de la primera fase.

La comparación entre los estilos en la campaña no tuvo una valoración pública, pese a la evidencia de cuáles eran las actuaciones que habían asegurado el elevado número de vacunados: si la intensa publicidad en los medios de comunicación pudo ser de gran importancia para estimular la participación en los entornos urbanos, en el medio rural fue la labor directa de los médicos APD la que permitió el éxito. El testimonio de Antonio Silván, médico titular de Chozas de Abajo durante la campaña piloto, ofrece una realidad cotidiana frecuentemente silenciada por el espectacular despliegue publicitario de las Jefaturas:

«Los médicos de APD siempre fuimos, hablo en general, yo creo que siempre fuimos muy partidarios de las vacunaciones porque era realmente una de nuestras armas, era una de nuestras armas... Porque la asistencia, la asistencia médica que podíamos prestar..., hombre, pues era importante, era importante médicamente y...

105 Establecemos el cálculo a partir de los porcentajes ofrecidos en el texto, que nos permiten establecer de forma aproximada el total de la población susceptible de recibir la vacuna que consideraron los equipos. En ningún momento se publicó este total, por lo que el porcentaje de vacunados que ofrecían las Jefaturas no podía ser comprobado. De hecho, el número real era desconocido para ellos mismos, pues como expresa Pérez Mel, partía de considerar que los niños entre dos meses y siete años «viene a ser algo más del 10 por 100 de la población total» (Pérez Gallardo, Vega Villalonga, Pérez Mel, López Villalba, Nájera MORRONDO (1964), p. 470).

106 Diario de León, 18-6-1963, p. 2; 9-7-1963, p. 4; 23-7-1963, p. 6; PROA, 23-7-1963, p. 3; 30-7-1963, p. 2. 
extramédicamente, porque claro era una asistencia... de, de... pudiéramos decir de conocimiento de la gente, de la familia, de cómo vivían, qué se podía, qué no se podía... Hay que tener en cuenta que en aquella época tenías que valorar mucho... tenías que valorar mucho... la cuestión económica de la gente. Porque entonces no había seguridad social, no tenían nada, tenían los famosos igualatorios que solucionaban problemas, pero, la gente... todo lo que representaba, por lo menos en la zona en que yo estaba, lo que representaba económicamente gasto pues restringía al máximo, porque era una zona empobrecida, una zona... lo que no es ahora, era entonces» $[. .$.$] «Hombre yo creo que... yo creo que la gente era consciente del pe-$ ligro que... que podía encerrar no vacunarse, yo creo que... y ahí éramos nosotros los que teníamos que influir en la, en la... Ya te digo, yo personalmente... no se me quedaba ni uno sin vacunar, porque si uno no iba, iba yo a buscarlo. $\mathrm{O}$ sea que... Entonces tenías todavía una autoridad sobre ellos. No, no, no quedaba, no quedaba nadie. Llamabas a su padre le explicabas... le explicabas... «ipor qué no vacunas al niño? Hombre, si no lo quieres vacunar, no lo vacunes; te expones a estos problemas, allá tú». O sea que... Eso, eso, eso en la... en la medicina rural, yo creo que, que vamos, las vacunaciones se llevaban al cien por cien» ${ }^{107}$.

\section{«LA SALK DE VIRUS INACTIVADOS QUE SE APLICA POR VÍA ORAL»: DIVULGANDO CONFUSIÓN}

Si la estrategia informativa sobre la poliomielitis había sido silenciar la auténtica morbilidad y la aparición de brotes epidémicos ${ }^{108}$ (aunque publicitando el riesgo de su aumento en España por ser enfermedad de países desarrollados) ${ }^{109}$, desde que se iniciaron las campañas del SOE en 1963 las autoridades sanitarias empezaron a reconocer públicamente la existencia de la poliomielitis y sus secuelas como forma de incentivar la vacunación. Pérez Gallardo también lo hizo advirtiendo de

«que la poliomielitis va en aumento en nuestro país [...] Si hasta ahora no se han dado más que dos mil casos al año, sin embargo los estudios epidemiológicos demuestran que están aumentando y que si no se toman medidas constituirá un grave problema» ${ }^{110}$.

Las cifras que durante el año 1963 utilizaron en las campañas todos los dirigentes fueron de dos mil casos de parálisis y doscientos fallecimientos anua-

107 Testimonio de Antonio Silván Garrachón.

108 PitA, Rodríguez SÁnCHEZ (2008), p. 332.

109 BALLESTER (2008).

110 El Progreso, 3-5-1963, pp. 3 y 8. 
les. Si bien ese número de fallecimientos se había superado en varias ocasiones, las estadísticas nacionales sólo habían reflejado en dos ocasiones una morbilidad poliomielítica superior a los dos mil casos, sin precisar si eran formas paralíticas, aunque, como ya indicamos al hacer referencia a la investigación de Sánchez Villares, era lo más probable por ser lo más visible. El dramatismo podía contemplarse ahora como un nuevo elemento eficaz en la publicidad y la campaña piloto permitió valorar si incrementando el temor a la enfermedad se conseguirían las cifras de participación necesarias para la erradicación. La introducción de la gratuidad en la vacunación posibilitó además una campaña sin las anteriores ambigüedades y en la que la responsabilidad pasaba del Estado a los individuos, pues la vacunación (pese a lo previsto en la Orden de 26 de enero) no era obligatoria ${ }^{111}$, lo que eximía al Estado de responsabilidad sobre los casos de polio posvacunal descritos en otros países $^{112}$.

Para fomentar este miedo no sólo se recurrió a las cada vez más frecuentes referencias a las secuelas, sino incluso a la imagen de la muerte como amenaza/castigo para quien no vacunase a sus hijos. Así se utilizó al «niño de Monforte» que apareció en toda la prensa nacional. El mejor momento para iniciar esta estrategia fue la conferencia de prensa de Camilo Alonso Vega, con la presencia de García Orcoyen y Pérez Mel, para hablar de vacuna antipolio y comunicar los buenos resultados de la campaña piloto:

«El director provincial de Sanidad de la provincia de LUGO, doctor Pérez Mel, que se hallaba presente en este coloquio, y que ha llegado esta mañana a Madrid, dijo que antes de salir de su residencia le habían notificado el fallecimiento de un niño en Monforte, a quien no habían querido vacunar como a los demás, en la campaña llevada últimamente allí» ${ }^{113}$.

Más adelante, Pérez Mel, en su memoria del año 1963, refirió este caso como el único que se había presentado, tratándose de un niño de quince meses, «niño no vacunado y procedente de otra provincia» ${ }^{114}$. El diferente matiz entre no haber sido vacunado por proceder de otra provincia, en la que no se

111 Orden de 26 de enero de 1963 de Ministerio de la Gobernación (B.O.E., 30-1-1963, nº 26, pp. 1649-50, p. 1650).

112 PAUl, J.R. (1971), A History of Poliomyelitis, New Haven - London, Yale University Press, p. 465.

113 El Progreso, 15-11-1963, p. 5.

114 «Memoria de actividades - Año de 1963. Jefatura Provincial de Sanidad de Lugo», A.H.P. Lugo, Fondos de Sanidad, Caja 27167. 
había hecho la campaña piloto, y lo aparecido en prensa, muestra a quién se iba a responsabilizar a partir de ese momento de la polio y sus secuelas.

Durante la campaña piloto se dirigieron mensajes a los padres, es decir, a las madres, pues como se citaba en una pequeña columna de «Temas locales» del Diario de León, al día siguiente del inicio de la campaña piloto, eran ellas quienes llevaban a los hijos a vacunar ${ }^{115}$. No sólo en el ámbito urbano, sino también en el rural, como recuerda Antonio Mallo, médico de San Emiliano (en la comarca de Babia):

«se convocaba a los niños en tal sitio, en la escuela generalmente, y allí aparecían los niños con sus madres... que, por cierto, allí eran muy cumplidores de todo eso, todo el mundo, venían las madres a vacunar a sus hijos... sí, sí allí todos siempre... no solamente la primera vez sino las revacunaciones» ${ }^{116}$.

Este papel de las madres fue también reconocido por Camilo Alonso Vega en su presentación de la Campaña Nacional, puesto que se basó en ello para esgrimir que no fuese necesaria la obligatoriedad de la vacunación:

«La conciencia de las madres españolas es más que suficiente para que la campaña sea un éxito. Tenemos la experiencia de las provincias de León y Lugo, donde, sin ningún genero de obligatoriedad, se superó la vacunación del 96 por ciento de los niños» ${ }^{117}$.

Dado que se asume que son las madres las que llevan a los hijos a vacunar, podemos entender que el siguiente aviso - que se repitió muy frecuentemente en prensa durante la campaña - iba dirigido a ellas: «Tu pereza para acudir a los Centros de vacunación puede significar mañana la invalidez para tus hijos. Protégelos con la vacuna por vía bucal» ${ }^{118}$. La pereza era considerada una tacha moral reprobable en una mujer, pero, muy especialmente, en una madre, puesto que la buena madre había de ser diligente en el cumplimiento de las órdenes médicas en materia de salud infantil119. Culpabilización, reconven-

115 Diario de León, 15-5-1963, p. 5.

116 Antonio Mallo, entrevista realizada el 15-8-2008.

117 PROA, 19-11-1963, pp. 1 y 5, p. 5.

118 El Progreso, 6-11-1963, p. 5 (repetido en días sucesivos durante la campaña).

119 La tradicional responsabilización/culpabilización del paciente en los casos de la salud infantil recayó en las madres, algo constatable durante todo el siglo y, muy especialmente, en las campañas contra la mortalidad infantil. Véanse como ilustrativos ejemplos AMICH ELÍAS, C. (2005), pp. 432-440; BernABeU Mestre (2002), pp. 131-140; JiMÉNEZ LuCENA, RuiZ SOMAVILla, CASTELlanos GuerRero (2002), pp. 208-211. 
ción y sarcasmo fueron recursos habituales para recordarles su papel: «Las mamás, sobre todo deben pensar la parte que les alcanza si no hacen por sus niños el 'tremendo sacrificio' de que se tomen un terroncito de azúcar... ¡Hay que ser más diligentes, señoras!...» ${ }^{120}$. Un rol de género tan asumido por las mujeres que no era necesario elaborar mensajes explícitos, resultando suficiente avisos de este tipo: «Más de 280 millones de personas han sido ya protegidas contra la parálisis infantil mediante la vacuna por vía bucal. 'El ser madre, es la dignidad mayor que se puede conocer en una mujer'» ${ }^{121}$.

Sin embargo, la divulgación no sólo trataba de promover la vacunación: también intentaba dar una imagen de la DGS como la responsable de esa cuestionada legitimidad sobre a quién pertenecía la medicina preventiva. Para ello era preciso presentar la caótica situación de dos organismos, que realizaban campañas simultáneas pero independientes con vacunas diferentes, como parte de una única y bien planteada estrategia. Si la Orden de 26 de enero ya intentaba mostrar ese control, el discurso debía elaborarse aún más, pues la campaña piloto mostraba el grado de confusión generado en la población.

Las informaciones aparecidas en la prensa de León nos permiten colegir el desconcierto creado por la prensa del Movimiento en los posibles destinatarios de los mensajes. Si en las ruedas de prensa de Sabin en febrero, Gerardo Clavero anunció el comienzo de la campaña masiva en dos meses ${ }^{122}$, el 20 de abril los lectores leoneses encontraban por primera vez una relación de poblaciones en las que se iba a efectuar la vacunación ${ }^{123}$. Se trataba, claro está, de la campaña con Salk del SOE. A partir de ese momento se sucederán informaciones alternativas en los periódicos, veladas réplicas y contrarréplicas, en las que al lector debía resultarle difícil distinguir campañas, vacunas y motivaciones. La confusión entre vacunas venía servida desde los propios medios de comunicación, que pusieron en boca de Pérez Gallardo la siguiente afirmación «[existen dos tipos de vacunas:] la Salk de virus inactivados que se aplica por vía oral, en forma de gotas incorporadas a un terrón de azúcar $[\ldots]\rangle^{124}$.

El problema más serio derivado de esta confusión entre vacunas y campañas, era convencer a las familias que acababan de efectuar la vacunación en el SOE de que debían repetirla en Sanidad. Pérez Gallardo insistió en sus conferencias y comunicados a diversos medios, pero fue Pérez Mel, en Lugo, quien más insistió y de forma más clara: había que administrar a los niños la vacuna

120 PROA, 30-7-1963, p. 2.

121 El Progreso, 26-5-1963, p. 2.

122 PROA, 9-2-1963, p. 4.

123 PROA, 20-4-1963, p. 3; Diario de León, 22-4-1963, p. 4.

124 PROA, 30-4-1963, p. 3. 
oral aunque hubiesen recibido la inyectable ${ }^{125}$. Y, el primer día de la campaña en Lugo, fue aún más rotundo:

«Por tanto, incluso los niños vacunados recientemente por el Seguro de Enfermedad mediante inyección - esto nos ha dicho textualmente el Jefe Provincial de Sanidad - deben vacunarse por vía bucal con la 'Sabin', porque así verán acrecentada notablemente su inmunidad contra el terrible mal».

Plantear la Sabin como simple mejora inmunitaria parecía la mejor vía para conseguir la participación en la campaña sin crear dudas sobre la Salk, criticar frontalmente al SOE o dar una imagen de total descoordinación. Una labor difícil que se llevó a cabo desde la Dirección General de Sanidad. Finalizada la campaña en León, García Orcoyen presentaba satisfecho la lucha contra la polio en España con los siguientes términos: «La actual campaña de vacunación por vía bucal [...] no es una iniciación, sino una etapa más en una cuidadosa preparación que arranca de la comenzada en $1958 » 126$. Porque si la polio era presentada como el obligado peaje de la incorporación de España al desarrollismo y las mejoras en la calidad de vida, los bien planificados cambios en la vacunación eran prueba de internacionalismo:

«En España se sigue así el camino por el que han marchado otros países de elevado nivel sanitario, que iniciaron sus campañas de vacunación con vacuna de tipo Salk, y que, deseando llegar a la erradicación de la poliomielitis, están actualmente realizando la vacunación con vacuna de virus vivos de tipo Sabin» ${ }^{127}$.

\section{UN ÉXITO GARANTIZADO}

La campaña piloto de vacunación antipoliomielítica fue un éxito porque debía ser un éxito, independientemente de los resultados. Así se lo había prometido Pérez Gallardo a Romay Beccaría ${ }^{128}$. Para garantizarlo no sólo se cuidaron todos los aspectos de la campaña y de su posterior seguimiento inmunológico, sino que el celo llegó a la previsión de cómo evitar que se difundiese el fracaso en caso de producirse. A tal fin, la poliomielitis tuvo el dudoso honor de ser la

125 El Progreso, 9-5-1963, p. 3.

126 Diario de León, 17-7-1963, p. 4.

127 «Nota de la Oficina de Información y Relaciones Públicas del Ministerio de la Gobernación, publicada en la Prensa del día 28 de marzo de 1963». En PéRez Gallardo, VeGA VILlalonga, PÉREZ Mel, LóPez Villalba, NÁJera Morrondo (1964), pp. 479-480, p. 480.

128 TuELls HERNÁNDEZ (2008), p. 323. 
primera enfermedad que abandonaba su nombre para ser sustituida por su código en la Clasificación Internacional de Enfermedades: la enfermedad 080. La pérdida de documentación no ha impedido que hayamos recuperado telegramas y circulares de la carpeta de Pérez Mel rotulada «Casos de polio 1964». Con insistencia se le recordaba desde la Inspección General que

«deberá enviar a esta Dirección telegráficamente los lunes, los casos de enfermedad cero ochenta que hubo en semana anterior, así como si no hubo. Continuará enviando a la Escuela Nacional de Sanidad comunicación al presentarse cada caso, según Circular de 14 de enero» ${ }^{129}$.

De toda la documentación consultada de la Jefatura Provincial de Sanidad de Lugo es la única enfermedad codificada.

Los niños afectados por las secuelas de la poliomielitis ofrecieron la emotiva imagen con que se enmascaraba la auténtica campaña librada en 1963 , episodio de una contienda más prolongada en el tiempo que enfrentaba a la Dirección General de Sanidad y al Seguro Obligatorio de Enfermedad. Los antecedentes de campañas de vacunación Salk desde 1958 se habían llevado a cabo a través de instituciones diversas, descoordinadas y con un seguimiento dispar según provincias, tanto por parte de las Jefaturas Provinciales de Sanidad como de la población, dispuesta a arriesgarse a contraer una enfermedad, a la que las autoridades restaban importancia, antes que a arruinarse comprando una costosa vacuna para la numerosa prole preceptuada por el Estado.

La gratuidad de la vacuna fue el emblema de la campaña de vacunación del SOE desde enero de 1963, así como la seguridad ofrecida al ser aplicada por los especialistas en pediatría. Estos reclamos fueron bien empleados en un despliegue publicitario sin precedentes en los medios de comunicación, por la intensidad y el uso de todos ellos, lo que comprendía desde avisos en prensa a cortometrajes de animación para cine y televisión. Los objetivos perseguidos no eran sólo la inmunización contra la polio, sino, principalmente, una construcción de una imagen del SOE apta para su inminente expansión a través de la Ley de Bases de la Seguridad Social. Desde los clásicos presupuestos de la revolución sanitaria propugnada por Falange, la lucha contra la polio les permitía ganar mayores competencias en materia de Medicina Preventiva, en detrimento de la Dirección General de Sanidad, y también seguir incrementando su autonomía administrativa en la relación con la industria farmacéutica ${ }^{130}$.

129 A.H.P. Lugo, Fondos de Sanidad, Caja 27190.

130 En España no existió una producción propia de vacuna, ni institucional ni de empresas privadas, por lo que la implantación de uno u otro tipo de vacuna se vio mediado por la impor- 
La campaña contra la poliomielitis de la DGS sólo puede ser comprendida en algunos de sus aspectos como respuesta a las actuaciones del SOE, que los forzaba a una actuación inmediata, gratuita y a nivel nacional. Desde la prematuridad de la Orden de 26 de enero de 1963, uno de los objetivos principales fue contrarrestar la debilidad mostrada, mediante una imagen de control y coordinación de toda la vacunación llevada a cabo en España, apoyada de forma decidida en el valor social creciente de la ciencia: si el SOE usó a los pediatras, la DGS recurrió a los expertos y a la divulgación para marcar la diferencia de la calidad científica. La consolidación de la virología fue evidente y la Sección de Virus de la Escuela Nacional de Sanidad pasó a transformarse en el Centro Nacional de Virus ${ }^{131}$. Las estrategias utilizadas para la consecución de estos objetivos fueron de tipo político (mediante el apoyo de Romay Beccaría) y mediático, en este caso fuertemente condicionado por la campaña desarrollada por el SOE. La propaganda en los medios estuvo dirigida en cada provincia por los Jefes de Sanidad y exhibieron la diferencia de estilos de los mismos en su interpretación de la sanidad, testimoniando lo que querían comunicar y lo que debían ocultar. De este modo el ensayo en León de la novedosa vacuna trivalente mediante una campaña piloto no llegó a ser conocido por la población ni por los médicos hasta un año más tarde, cuando se vio publicada la memoria en las páginas de la Revista de Sanidad e Higiene Pública.

El «éxito garantizado» tuvo su recompensa epidemiológica y la poliomielitis experimentó un espectacular descenso en España. Un éxito contraproducente, pues el sueño de la erradicación estaba aún lejos: las estadísticas de 1966 empezaron a mostrar un nuevo incremento de la morbilidad, con unos 300 casos anuales, que incluso se presentaron como brotes epidémicos en 1975 en Cádiz $^{132}$. Pero, con un número exiguo de afectados, la poliomielitis ya no constituía un problema sanitario prioritario y la Cuarta Campaña Nacional de Vacunación apenas generó publicidad en prensa ${ }^{133}$. Su destino estaba anunciado desde el momento en que pretendieron ocultar su incómodo nombre bajo el

tación de la misma y los acuerdos/contratos con los laboratorios extranjeros. Las circunstancias particulares de España, con un régimen dictatorial, pero sin centralización real de la política sanitaria debido a una manifiesta descoordinación de la misma avalarían las reflexiones de LiNDNER Y BLUME (2006) al modular con estudios transnacionales la hipótesis de Hollinngsworth, Hage y Hanneman.

131 NÁJera Morrondo, R. (2006), El Instituto de Salud Carlos III y la sanidad española. Origen de la medicina de laboratorio, de los Institutos de Salud Pública y de la investigación sanitaria, Revista Española de Salud Pública, 80(5), pp. 585-604, p. 597.

132 BALLESTER (2008).

133 MuÑOZ Singi (2007). 
aséptico de «enfermedad 080», aunque la realidad de las personas con poliomielitis desmintiese que unas cuantas campañas le hubiese supuesto al Estado franquista ganar también esta guerra.

Fecha de recepción: 8 de octubre de 2008 .

Fecha de aceptación: 15 de enero de 2009. 